Fabiane Olegário

Universidade Federal do Rio Grande do Sul, UFRGS

E-mail: fabijj10@yahoo.com.br

(D) http://orcid.org/0000-0001-6855-3064

Sandra Mara Corazza

Universidade Federal do Rio Grande do Sul, UFRGS

E-mail: sandracorazza@terra.com.br

(D) https://orcid.org/0000-0002-1237-198X

Recebido em: 23/12/2017

Aprovado em: 17/04/2019

\section{Ler e escrever arquivos: uma prática tradutória} em educação

\section{Fabiane Olegário Sandra Mara Corazza}

\section{Resumo}

Este texto pensa os processos de ler e escrever como modos de traduzir os arquivos existentes. Tomando como aporte teórico o pensamento da diferença proposto por autores como Roland Barthes, Michel Foucault e Jacques Derrida, além de teorizações literárias acerca da tradução com o poeta e tradutor brasileiro Haroldo de Campos, o texto compreende o arquivo como texto vivo e aberto às interferências do leitor e escritor, que ao ler reescreve o texto, traduzindo-o criticamente. A partir desta perspectiva, defende a reinvenção de textos originais pelo educador-tradutor, na medida em que transcria as matérias que transitam nos arquivos pelo veio da leitura-e-escrita. Baseado em tal premissa, o texto conclui que a prática de ensinar só é possível porque o educador transforma as matérias do currículo e da didática por meio de uma tradução transcriadora e crítica dos arquivos.

Palavras-chave: Arquivos. Tradução. Ler-e-escrever.

http://www.perspectiva.ufsc.br http://dx.doi.org/10.5007/2175-795X.2019.e54650 
Abstract

Keywords:

Files.

Translation. Read-and-write.

\section{Resumen}

Palabras clave: Archivos. Traducción. Leer-y-escribir.

\section{Reading and writing files: a translation practice in education}

This text regards the processes of reading and writing as ways of translating existing files. By taking the thought about difference proposed by authors such as Roland Barthes, Michel Foucault and Jacques Derrida as a theoretical contribution, besides literary theorizations about translation as seen by the Brazilian poet and translator Haroldo de Campos, this text understands the file as a living text that is open to interferences by the reader and writer, who rewrites the text while reading, thus translating it critically. From this perspective, it defends the reinvention of original texts by the translator-educator, as he transcreates the matters that move in the files through reading-and-writing. Based on this premise, the text concludes that the teaching practice is only possible because the educator transforms the matters of both the curriculum and the didactics by means of a transcreating and critical translation of the files.

\section{Leer y escribir archivos: una práctica de traducción en educación}

Este texto piensa los procesos de leer y escribir como modos de traducir los archivos existentes. Tomando como aporte teórico el pensamiento de la diferencia propuesto por autores como Roland Barthes, Michael Foucault y Jaques Derrida, además d teorizaciones literarias acerca de la traducción, como el poeta y traductor brasilero Haroldo de Campos, el texto comprende el archivo como un texto vivo y abierto a las interferencias del lector y escritor, que al leer, reescribe el texto, traduciéndolo críticamente. A partir de esta perspectiva, se defiende la reinvención de textos originales por el educador-traductor, en la medida que transcrea las materias que transitan en los archivos por la veta de la lectura-y-escritura. Basado en esta premisa, el texto concluye en que la práctica de enseñar sólo es posible porque el educador transforma las materias del programa y de la didáctica por medio de una traducción transcreadora y crítica de los archivos. 


\section{Introdução}

Neste texto, propõe-se pensar nos processos de leitura e de escrita como movimentos tradutórios e renovadores dos arquivos existentes. Toma as teorizações de Michel Foucault e Jacques Derrida no que tange ao conceito e aos modos de funcionamento dos arquivos, visto que estes não cessam de produzir práticas discursivas, memórias e esquecimentos. Proliferador de paradoxos, o arquivo, como texto vivo, maleável e dobrável, abriga instabilidades e incertezas, devido à sua abertura para o mundo. Nesse sentido, os arquivos são textos abertos ao cosmos e cintilam em um ponto da galáxia, movimentam-se e transformam-se, na medida em que leitores e escritores tomam suas matérias a fim de reinventar uma vida nova para os textos.

Além disso, compreende-se que a leitura e a escritura são práticas intrínsecas. Por isso, os arquivos correspondem a textos constantemente modificados pelas interferências do leitore-escritor. Sendo assim, as práticas de ler-e-escrever são manifestações concretas do ato de atribuir sentidos ao texto. Importa frisar que o sentido que atribuímos às coisas de modo geral “não deve ser descoberto, restaurado nem reempregado, mas deve ser produzido por novos maquinários. Ele não pertence a nenhuma altura, não está em nenhuma profundeza, mas é efeito de superfície" (DELEUZE, 2011, p.75). Se o sentido é produzido e transformado, não dirá respeito à recognição ou reconhecimento, tampouco à imagem dogmática do pensamento. Não há no sentido uma origem perdida, nem sequer uma parada no transcendente, porque o sentido não equivale ao significado, mas à geração de outros sentidos ainda não pensados. $\mathrm{E}$ eis que, "abolido o sentido, tudo fica por fazer" (BARTHES, 2012, p.85).

Como práticas simultâneas - ler e escrever em um único gesto -, não há nessa relação nenhuma primazia, nem privilégio exclusivo de uma sobre a outra. A leitura verdadeira, segundo Blanchot (1987), não quer saber o que o autor quis dizer exatamente e qual é a verdade que o texto anuncia, pois, de um modo ou de outro, um texto reivindica a coautoria do leitor. O texto está sempre aberto a novas ingerências praticadas pelo pensamento. Nessa medida, o texto situa-se em um “jogo interminável de significantes, impossíveis de serem aprisionados numa significação plena" (CORAZZA, 2000, p.94). Assim, "texto, leitor e escritor tornam-se simulacros, uma vez que estão sempre diferindo de si e do modelo" (HEUSER, 2016, p.28), em um processo intermitente de transformação tradutória das matérias que constituem os arquivos.

A prática tradutória é compreendida como uma atividade transcriadora de textos de partida, sendo urdida em meio aos encontros transculturais, transdisciplinares, translinguísticos e transemióticos, e "exprime, desde logo, uma insatisfação com a ideia 
'naturalizada' de tradução, ligada aos pressupostos ideológicos de restituição da verdade" (CAMPOS, 2013, p.79).

É da natureza da tradução não ter a função de traduzir o conteúdo, palavra por palavra, linha por linha, de forma literal, pois a transcriação do texto-fonte está implicada na "construção de uma tradição viva [...] que se rege pelas necessidades do presente de criação" (CAMPOS, 2013, p.39). Todavia, não se traduz apenas o conteúdo do texto original, visto que a tradução é uma questão de arte, e, por tal motivo, incide no texto poético a impossibilidade de tradução, e o tradutor empenha-se ao máximo para traduzir o intraduzível. É em meio à impossibilidade de tradução que se "engendra o corolário da possibilidade e também de recriação desses textos" (CAMPOS, 2013, p.4).

\section{Arquivos}

Sabemos que os arquivos existem desde o advento da escrita, embora se tenha conhecimento de que na antiga Mesopotâmia, 4000 a. C., já havia a presença de arquivos na escrita cuneiforme. Esse sistema de escrita foi desenvolvido pelos sumérios, que se utilizaram de placas de barro úmido (como suporte da escrita) e um objeto em formato de cunha (instrumento de madeira ou ferro usado para o registro nas placas). Nelas, eles registravam fatos cotidianos referentes à administração, à economia e à política da época. Após a inscrição, as placas eram expostas ao sol, ou então cozidas ao forno, com o objetivo de conservar as informações nelas marcadas. Nesse sentido, os sumérios foram os primeiros a instituírem formas de manter guardados os registros feitos, e o conjunto desses registros constituiu o arquivo de uma determinada época.

De modo corriqueiro, o arquivo é compreendido como um local de armazenamento de documentos - fotografias, cartas, registros oficiais - , com o objetivo de conservar uma memória passada, que pode, no presente, ser acessada pelos humanos. Nessa perspectiva, é muito comum imaginar o arquivo como um depósito de documentos amarelados, carcomidos e dispostos em alguma pilha ligeiramente empoeirada (FARGE, 2009). Para a arquivologia, o arquivo está "sempre ligado à noção de patrimônio, de construção de identidades sociais e de fortalecimento dos mecanismos de memórias" (AQUINO; VAL, 2017, texto digital). Para mantê-lo intacto, foi preciso desenvolver determinadas técnicas, capazes de preservar o conteúdo arquivado, o que implica pensar nas relações que se estabelecem entre os modos de arquivamento e suas respectivas técnicas.

Independentemente do modo e da técnica de arquivamento, todos os arquivos - ou a maioria - comungam da acepção de conservação de documentos. A preservação do objeto arquivado garante - ou pelo menos é isso que almeja - a sua durabilidade e, 
consequentemente, a sua acessibilidade. A partir de uma visão clássica, poderíamos afirmar que o arquivo tem como tarefa salvaguardar um conjunto de informações referentes ao passado. Essa forma de pensar vai ao encontro da acepção logocêntrica, que pensa o arquivo como um depositário de documentos, cujo registro revela um importante fato. Ademais, atribui ao arquivo uma função social, ou seja, uma espécie de banco de dados.

Além da concepção logocêntrica, que constitui a imagem de arquivo, é possível pensálo sob o viés de outras perspectivas teóricas. Tal tarefa nos conduz a Michel Foucault (2007) e a Jacques Derrida (2001b), em suas respectivas obras, Arqueologia do Saber e Mal de Arquivo: uma impressão freudiana. Entre ambos, há uma aproximação no que se refere à acepção de arquivo, pois recusam as noções de essência e de origem, desconstruindo a imagem clássica e logocêntrica de arquivo, embora se distanciem no modo de análise, constituindo campos analíticos distintos.

\section{Das coisas ditas}

O teor analítico do arquivo, no viés foucaultiano, requer, sobretudo, atenção às formações históricas, atravessadas por um campo social e pelas relações de poder e de saber. Foucault (2007), na obra Arqueologia do Saber, refere-se ao arquivo como:

[...] a lei do que pode ser dito, o sistema que rege o aparecimento dos enunciados como acontecimentos singulares. Mas, o arquivo é também o que faz com que todas as coisas ditas não se acumulem indevidamente em uma massa amorfa, não se inscrevam, tampouco, em uma linearidade sem ruptura e não desapareçam ao simples acaso de acidentes externos, mas que se agrupem em figuras distintas, se mantenham ou se esfumem segundo as regularidades específicas; ele é o que faz com que não recuem no mesmo ritmo que o tempo, mas que brilham muito forte como estrelas próximas venham até nós, na verdade de muito longe, quando outras contemporâneas já estão extremamente pálidas (FOUCAULT, 2007, p. 147).

$\mathrm{Na}$ entrevista com Brochier, publicada na revista Magazine Littéraire, em 1969, sob o título "Michel Foucault Explica seu Último Livro" (Arqueologia do Saber), Foucault (2008, p.145) ressalta que o arquivo se constitui pelo "conjunto de discursos efetivamente pronunciados; e esse conjunto é considerado não somente um aglomerado de acontecimentos que teriam ocorrido [...] mas um conjunto que continua a funcionar, a se transformar através da história, possibilitando o surgimento de outros discursos", constituídos através dos enunciados. As coisas ditas, às quais se refere, remetem ao conjunto de enunciados - não há enunciado que sobreviva isolado de outros enunciados - que colaboram na formação do discurso.

Sob essa visão, a análise do arquivo pressupõe investigar a espessura material dos enunciados enquanto formação e materialização do discurso, como também o modo de 
dispersão dos enunciados que são localizáveis, porque, segundo Foucault (2007), os enunciados marcam dinamicamente o tempo histórico e social. Além disso, os comportamentos (formas de existência) e a mentalidade (produção da subjetividade) dependem dos enunciados que se entrelaçam no falar (dizível) e no ver (visível).

A arqueologia, segundo Foucault (2007, p.174), "descreve os discursos como práticas específicas no elemento do arquivo". Dessa maneira, o arquivo é construído pela "massa das coisas ditas em uma cultura, conservadas, valorizadas, reutilizadas, repetidas e transformadas" (FOUCAULT, 2014, p.52). É preciso interrogar o arquivo com vistas a instituir uma história do presente. Em coro com Deleuze (2005, p.29), salientamos que o enunciado não advém de um sujeito, não remete a nenhum cogito, tampouco diz respeito à metafísica, pois "tudo é real no enunciado, e nele toda a realidade se manifesta".

É no arquivo que os enunciados se materializam, pois é ele que autoriza o que pode ser dito em uma determinada época. Nesse sentido, o arquivo é a "lei do que pode ser dito" (FOUCAULT, 2007, p.147). Ao anunciar que o arquivo é o sistema que mantém as coisas ditas, segundo regras específicas, as quais se materializam no discurso, Foucault (2007) afirma a existência da lei da raridade dos enunciados, capaz de determinar o aparecimento e o desaparecimento dos enunciados. Isso mostra que nem tudo pode ser dito, nem por qualquer sujeito, nem em qualquer lugar, devido às leis e às regularidades enunciativas. Assim, demonstra-se que poucas coisas podem ser ditas (DELEUZE, 2005).

Ademais, é preciso sublinhar que o arquivo não diz respeito aos grandes acontecimentos históricos, pois, segundo Deleuze (2005, p.28), “o arquivista geralmente evita citar grandes nomes". Atento às formações discursivas e não discursivas, o arquivista acompanha a transformação dos elementos que as constituem: o enunciado, que tem a função de viabilizar a existência e a recorrência dos discursos. Logo, o arquivo refere-se àquilo que está na ordem do discurso e não pode ser "descritível em sua totalidade" (FOUCAULT, 2007, p. 148). O enunciado não cessa de variar, de ir de um sistema a outro; ele é "transversal", sendo este movimento responsável pela formação de "grupo ou uma família de enunciados" (DELEUZE, 2005, p.17).

Como já mencionado, o enunciado isolado não sobreviveria, sendo que, para existir, sempre necessitará de outros enunciados, que se constituem no interior de uma rede enunciativa, formando uma plataforma de discurso e revelando a sua dupla face: discursiva e não discursiva. Trata-se de um conjunto de enunciados, distribuídos em séries, que se conectam a outras séries antecedentes, as quais são reatualizadas incessantemente, uma vez que se relacionam com os enunciados que as sucedem. 
No trabalho arqueológico empreendido por Foucault, os enunciados dispersam-se, acumulam-se, opõem-se, conservam-se e modificam-se. Movimentos concedem a existência do arquivo. Além disso, vale lembrar que os enunciados são raros e, sobretudo, cumprem determinada regularidade. No entanto, não correspondem às frases gramaticais, pois "para o enunciado não basta uma construção linguística" (ARAÚJO, 2008, p.61), nem às proposições lógicas e tampouco ao ato de fala. Isso porque os enunciados têm como princípio a raridade; por tal razão é que se distinguem das frases emitidas e encontradas em abundância. Não há “sujeito gramatical, nem mesmo sujeito lógico" (ARAÚJO, 2008, p.62). Desse modo, “o enunciado circula, serve, desnuda-se, permite ou impede a realização de um desejo, é dócil ou rebelde a interesses" (FOUCAULT, 2007, p.138).

Partindo dessas premissas sobre a compreensão do arquivo em Foucault, configura-se uma relação entre a verdade e o enunciado. Na medida em que a formação discursiva plataforma de enunciados - é disseminada como verdade, o discurso passa a ser legitimado como tal, ao passo que reproduz as séries enunciativas. Esse aspecto, embora à primeira vista possa parecer óbvio, permite elaborar a suspeita atinente ao processo de recriação, pois, se considerarmos que "a verdade é deste mundo" (FOUCAULT, 2012, p.52), é porque, de um modo ou de outro - tal como o conhecimento -, ela foi inventada "em qualquer canto longínquo do universo difundido no brilho de inumeráveis sistemas solares" (NIETZSCHE, 2001, p.64). Portanto, "a vontade de verdade requer uma crítica - com isso determinamos nossa tarefa -, o valor da verdade será experimentalmente posto em questão" (NIETZSCHE, 1998, p.140).

Com efeito, o arquivo, na perspectiva foucaultiana, não é apenas um depositário privilegiado e silencioso daquilo que, em certa medida, coube aos discursos construir em uma determinada época. Ao contrário da imagem de um arquivo estável e taciturno, ele irradia ruídos e murmúrios enunciativos de uma época específica, sendo incapaz, no entanto, de suportar o confinamento. Nesse sentido, o arquivo incita "uma algavaria de vozes que reclamam seu direito de ir e vir, contra toda a forma de contingenciamento narrativo" (AQUINO, 2016, p.195). Isso porque o arquivo abriga tensões discursivas, as quais "forjam as composições de sentidos que somos eventualmente capazes de operar com os ecos veridictivos do passado" (AQUINO, 2016, p.195). 
A ordem não está mais garantida ${ }^{1}$

No que tange à análise de Derrida acerca do arquivo, ocupamo-nos da obra Mal de Arquivo. Uma impressão freudiana. Primeiramente, a obra fora intitulada por Derrida como $O$ conceito de arquivo. Uma impressão freudiana e apresentada na Conferência sobre Memória e Arquivo na França em 1994. Ao publicá-la, no ano seguinte, acabou sendo renomeada para Mal de Arquivo. Uma impressão freudiana. Com essa obra, Derrida coloca em xeque o estatuto do pensamento clássico e logocêntrico, a partir da assinatura freudiana no próprio arquivo. Derrida faz funcionar a sua estratégia operatória - a desconstrução - e a desmontagem/remontagem do texto ocorre sempre no interior dele mesmo, mostrando que o princípio que forma o texto é o mesmo da sua ruína.

Derrida (2001b, p.47), contrário à ideia de conceito como definição, parece debater-se sobre o conceito de arquivo, pois "dispor de um conceito, ter segurança sobre seu tema é supor uma herança fechada". Na busca pelo entendimento de arquivo, Derrida encontra a palavra arkhé, que designa começo, origem, memória; e arkhe, que significa comando. Portanto, em arkhé e arkhe, o arquivo refere-se a dois sentidos: origem e comando; já arkheiôn denota casa, domicílio, morada, residência. Salvaguardado no arkheiôn e sob a vigília do "dono" da casa, o arconte - magistrado grego -, responsável pelo zelo e manutenção do arquivo que havia na casa, tem autorização para interpretá-lo. Contudo, o acesso à interpretação reforça a necessidade de consignação do arquivo, pois não requer apenas reunir os signos em um único lugar, conferindo-lhe unidade e, sobretudo, dar-lhe um "suporte estável e a disposição de uma autoridade hermenêutica legítima" (DERRIDA, 2001b, p.13), mas tornar executável o poder arcôntico, cuja tarefa pressupõe concentrar, unificar e identificar os signos, conferindo, desse modo, o poder de consignação.

Porém, o arquivo derridiano é atacado por um mal que ele próprio produz no seu interior, cujo efeito é contra si mesmo. O mal configura-se na destruição do arquivo, sendo essa a condição primeira de sua produção. Sobre a pulsão de morte, Derrida (2001b) explica:

Ela destrói seu próprio arquivo antecipadamente, como se ali estivesse, na verdade, a motivação mesma de seu movimento mais característico. Ela trabalha para destruir o arquivo: com a condição de apagar, mas também com vistas a apagar seus "próprios" traços - já que não podem desde então serem chamados de "próprios". Ela devora seu arquivo, antes mesmo de tê-lo produzido externamente (DERRIDA, 2001b, p.21, grifos do autor).

Atingida pela pulsão de morte, a memória seria a primeira a sofrer os efeitos dessa violência, resultando em sérios esquecimentos, e o borramento do arquivo será inevitável. O

\footnotetext{
${ }^{1}$ Frase de autoria de Jacques Derrida (2001, p.15).
} 
arquivo, portanto, só poderá ser reconstituído devido à concorrência entre memória e esquecimento. Ideia avessa ao conto de Borges (2007, p.105), em que o personagem borgiano Ireneo Furnes apresenta uma memória absoluta, pois tem "mais lembranças que terão tido todos os homens desde que mundo é mundo". A memória de Furnes vai de encontro à ideia de arquivo que é marcado pela tensão profunda e desarmônica entre lembrança (memória) e esquecimento (amnésia). Verdadeira zona de combate, pois, na medida em que o arquivo é atingido pela pulsão e morte, ele também arma trincheiras e resiste aos golpes destrutivos do seu material. É nesse campo paradoxal que o arquivo "tem em lugar da falta originária e estrutural da chamada memória" (DERRIDA, 2001b, p.21), o esquecimento, visto que é produtor de memórias e gerador de arquivos. Furnes, personagem borgiano, mostra-se incapaz de arquivar, pois “sua percepção e sua memória eram infalíveis” (BORGES, 2007, p.104).

O que restaria do arquivo após as rasuras, borramentos? Teríamos apenas os seus rastros como pontos de aproximação com o material arquivado? Que condição teria o exterior de ler os seus rastros, conferindo-lhe um novo suporte? Haveria arquivo sem a possibilidade de inscrição e sem suporte? O que estaria em jogo na leitura dos rastros de um arquivo? Todo rastro, segundo Derrida (1997), é rastro de outro rastro.

Mesmo diante de tantas suspeitas e questões, podemos afirmar que todo arquivo carrega o seu próprio mal e que seu destino é sua destruição concomitante com sua produção. É como se o arquivo portasse em si mesmo: o zelo e o aniquilamento; a prática de conservação e a necessidade de apagamento; a memória e o esquecimento. É um mal borrador que aflige a memória, multiplicando as repetições do arquivo. Nada seria mais ingênuo do que creditar ao arquivo a função de somar e acumular os registros documentais, sem uma técnica externa de repetição e de seleção. Enfim, o arquivo tem vida própria e, por essa razão, porta o seu mal; portanto, não há nada a fazer, senão tomar os seus rastros, o que não significa romper com a sua materialidade gráfica, nem sequer confiná-la (DERRIDA, 1997). O rastro não pode ser identificado, classificado, mensurado e ordenado a priori. Um rastro mostra que a existência do arquivo revela o seu caráter inconclusivo e incompleto.

Ler e escrever os rastros do arquivo institui, ao mesmo tempo, um ato "conservador e revolucionário, formação histórica e devir, tradição e tradução luciferina” (CORAZZA, 2017, p.10). Diante dos rastros, o escrileitor (escritor-e-leitor) ensaia gestos, risca e apaga os traços, engendrando verdadeira arquitetura do rastro. À sua maneira, empreende tentativas de reconfigurá-los e, por isso, traça-os novamente, visto que "nada [...] está, jamais, em qualquer lugar, simplesmente presente ou simplesmente ausente. Não existe, em toda a parte, a não ser diferenças e rastros de rastros" (DERRIDA, 2001a, p.32). 
$\mathrm{Na}$ impossibilidade de conceituar o arquivo, Derrida insiste em deixá-lo aberto ao afirmar a existência de um "quase-conceito". Daí a sua preferência por empregar o termo "quase-conceito", com o qual é possível evocar um arquivo que não permite ser confinado e petrificado. Derrida está na contramão da acepção de conceito que, ao ser definido, assume uma identidade. Nessa perspectiva, o "quase-conceito" de arquivo implica, de certo modo, estabelecer uma nova relação com as matérias que o constituem. A transmutação do conceito (fechado) em "quase-conceito" (aberto) não se dá pela substituição de um pelo outro, mas pelo confronto que se estabelece entre a tradição e a experiência irredutível do futuro (DERRIDA, 2001b).

A noção aberta de arquivo faz proliferar múltiplas inscrições, que se fazem em meio a outras tantas; na medida em que o arquivo se distancia da origem, afirma as técnicas de repetição e as formas de arquivamento. Esse fluxo de inscrições não significa repetir o passado, pois "trata-se do futuro, a própria questão do futuro, a questão de uma resposta, de uma promessa e de uma responsabilidade para o amanhã” (DERRIDA, 2001b, p.50).

Desse modo, ler e escrever operam no desenvolvimento da técnica de repetição do arquivo. Uma técnica constituída por fluxos imprevisíveis em que as matérias passam por processos de desconstrução, solicitando novos rearranjos. O ato de remontar o arquivo propicia o "gesto variável de subordinações enunciativas de blocos, de idas e vindas de dobras e redobras da tópica e da reunião e da articulação de seus borramentos - nesse conjunto se percebe um só movimento de criação do arquivo" (DINARTE, 2016, p.12).

Uma força plástica dobra e redobra o arquivo de modo revolucionário e anárquico. A vontade de querer lê-lo e reescrevê-lo é tecida pelas dobras, que se desdobram e redobram continuamente. $\mathrm{O}$ arquivo é texto, sendo que a sua existência depende do que fizermos dele no momento presente. Assim, é preciso observar a técnica de repetição engendrada no arquivo, pois o que será determinante no processo de arquivamento não se refere ao conteúdo, mas à técnica empregada no ato de arquivar, sendo função da técnica definir o que será de fato arquivado.

$\mathrm{O}$ arquivo vivo e aberto vai de encontro à acepção de um arquivo cuja funcionalidade é meramente técnica, um arquivo que reúne um conjunto de letras-mortas; isso porque ele se relaciona com o futuro, o que requer necessariamente a desmontagem e remontagem das matérias que nele habitam. No entanto, essa atividade só pode ser acessada via leitura e escrita do material arquivado. O tradutor lida com matérias advindas de outras instâncias, tanto espacial, quanto temporal. É certo que, em se tratando de arquivo aberto, estaremos sempre entrelaçados no "presente passado, presente atual e presente futuro" (BIRMAN, 2008, p.110). 
$\mathrm{O}$ arquivo, nesse sentido, não se vincula apenas ao passado, mas remete-se ao futuro. "Trata-se do futuro, a própria questão de futuro, a questão de uma resposta, de uma promessa, e de uma responsabilidade de amanhã" (DERRIDA, 2001b, p.50). Portanto, o arquivo relaciona-se com aspectos éticos, uma vez que está sob o poder arcôntico, que articula memória, tradição e crítica. Estamos nos referindo não somente à técnica do material arquivado, mas, sobretudo, à responsabilidade com este material, visto que, a partir do momento em que o tomamos para lê-lo e reescrevê-lo, o arquivo é atacado por processos desconstrucionistas.

A noção de tela desconstrucionista em Derrida esclarece que todo arquivo necessita de um suporte onde as matérias são organizadas e arranjadas, em uma estrutura desmontável. Não sendo possível fixá-lo, tampouco tratá-lo como inerte, o arquivo lança-se na aventura de ser novamente suplementado. Há nisso tudo uma forte suspeita de que um arquivo não exista enquanto arquivo-morto. Tudo nos leva a crer que o arquivo tem vida própria, uma vez que é interpelado por uma pulsão anárquica, que o ataca, levando à amnésia (DERRIDA, 2001b).

Além disso, destacamos o paradoxo instalado no contraditório movimento que se configura entre as práticas de lembrar (memória) e esquecer (amnésia). O esquecimento apaga uma parte constituinte da memória e, com isso, assegura a repetição do material arquivado. Trata-se de repetir o "irrecomeçável” (DELEUZE, 1988, p.22), pois não há arquivo que não dependa de uma técnica de repetição. Portanto, afirmamos que todo arquivo tem como procedência a invenção, o que consiste em "repetir, a reproduzir, cada vez em sua unicidade original, pois um arquivo deve ser idiomático, e ao mesmo tempo ofertada e furtada à tradução" (DERRIDA, 2001b, p.118).

A vida é uma questão de arquivo, assim como toda "invenção depende de um arquivo" (ADÓ, 2013, p.102), embora nem o arquivo nem a invenção sejam possíveis "sem uma certa exterioridade". Isso significa dizer que "não há arquivo sem exterior" (DERRIDA, 2001b, p.22). A existência do arquivo depende dos processos tradutórios, de práticas de leitura e de escrita que atribuem sentidos ao texto.

Os sentidos produzidos pela via da leitura e da escrita dos arquivos são recriados pelo leitor-e-escritor, que insiste em tocar o intocável, desestabilizar o estável e penetrar no impenetrável do arquivo. A pulsão de morte desencadeada pelo próprio arquivo, de pronto, aciona o processo de produção da sua diferença. Por essa razão, recorre à repetição, pois há “sempre por fazer, por desfazer e refazer e em um minuto aquele já se faz distante!" (DE ARAUJO, 2007, p.22).

Encontramos, nos arquivos, vidas que se reúnem transitoriamente em uma "estrutura espectral: nem presente nem ausente em carne e osso, nem visível nem invisível" 
(FONSECA, 2010, p.33). Vidas que procuram uma morada "para se abrigar e também para dissimular" (DERRIDA, 2001b, p.13), mesmo que saibam o quão arbitrária será existir em meio aos arquivos, já que estes possibilitam um "encontro improvável entre as matérias heterogêneas, assimétricas e, no limite, incomunicáveis" (AQUINO, 2016, p.189). Em meio a tantas vidas que produziram os arquivos, o educador-tradutor tem a necessidade de reimaginar as matérias arquivadas, que não podem ser mensuradas nem categorizadas por algum critério classificatório dotado de valores transcendentes, visto que carregam a potência de mais vida. Se houver regras, portanto, só lhe interessam aquelas que forem verdadeiramente inventadas. Transladadas e transformadas, as matérias que compõem os arquivos partem em direção a terras estranhas, experimentando novos arranjos por meio de conexões inventivas.

\section{Considerações finais:}

Ao lidar com os arquivos por meio da leitura e da escrita tradutórias, o educadortradutor renova as matérias que os constituem. Nessa direção, o texto afirma que o educador é criador de novos arquivos, uma vez que toma as matérias originais dos arquivos do mundo para ensinar.

$\mathrm{Na}$ medida em que defendemos a prática tradutória de arquivos como recriação de didática e do currículo escolar, consideramos que os processos educativos estão implicados na capacidade de produzir outros textos, ou seja, a partir do texto de partida - arquivo -, inventam novas linhas, traçam e retraçam formas de conteúdo para fantasiar novas formas de expressão.

Assim, o educador-tradutor não compreende o arquivo e tampouco se refere a ele como um texto original capaz de carregar, em última instância, a verdade inquestionável do mundo, mas como um texto crivado de complexidades e paradoxos que se situa entre os limites do que pode ser dito e as suas interdições. O que está em jogo são os modos de leiturae-escrita dos arquivos. Como são lidos no campo da educação? De qualquer forma, os arquivos são engendrados por movimentos tradutórios que, por conseguinte, são decisivos no momento do arquivamento. Em outras palavras, ler e escrever instauram uma prática de renovação e repetição das matérias arquivadas.

Portanto, uma tradução crítica e inventiva não traduz palavra por palavra, frase por frase do texto original, pois há sempre um grau, uma medida não quantificável de criação. Por tal motivo, o arquivo é transfigurado, transformado, arruinado enquanto texto primeiro. Nesse sentido, o leitor-e-escritor cria linhas (que não estão nas entrelinhas) dentro do texto original, que se efetiva na medida em que trai a língua de partida e passa a entoar um canto paralelo, que "deixa de ser fiel ao significado textual para ser inventivo" (CAMPOS, 2013 p.18). 


\section{Referências}

ADÓ, Máximo Daniel Lamela. Educação potencial: autocomédia do intelecto. Tese (Doutorado em Educação). 2013. 195p. Programa de Pós-Graduação em Educação, Faculdade de Educação, Universidade Federal do Rio Grande do Sul, Porto Alegre, 2013.

ARAÚJO, Inês Lacerda. Foucault e a crítica do sujeito. 2 ed. Curitiba: Ed. Da UFPR, 2008.

AQUINO, Julio Groppa. Não mais, mas ainda: experiência, arquivo, infância. Revista Childhool e Philosophy. Rio de Janeiro, v.12, n.23, jan.-abr. 2016. (p.179-200).

AQUINO, Julio Groppa; VAL, Gisela Maria do. Uma ideia de arquivo: contributos para uma pesquisa educacional. Pedagogia y saberes. 2017. (no prelo).

BARTHES, Roland. O rumor da língua. Tradução Andréa Stabel. São Paulo: Martins Fontes, 2012.

BIRMAN, Joel. O arquivo e o mal de arquivo: uma leitura de Derrida de Freud. Revista Natureza Humana, v.10, n.1, 2008. (p.105-128)

BLANCHOT, Maurice. O espaço literário. Tradução Álvaro Cabral. Rio de Janeiro: Rocco, 1987.

BORGES, Jorge Luis. Ficções. Tradução Davi Arrigucci Jr. São Paulo: Companhia das Letras, 2007.

CAMPOS, Haroldo de. Haroldo de Campos - Transcriação. (Org. Marcelo Tápia, Thelma Médici Nóbrega). São Paulo: Perspectiva, 2013.

CORAZZA, Sandra Mara. O que faz gaguejar a linguagem da escola. In: ENDIPE (Encontro Nacional de Didática e Prática de Ensino). Linguagens, espaços e tempos no ensinar e aprender. Rio de Janeiro: DP\&A, 2000.

CORAZZA, Sandra Mara. Inventário de Procedimentos didáticos de tradução: teoria, prática e método de pesquisa. Revista Brasileira de Educação. 2017. (no prelo).

DE ARAUJO, Róger Albernaz. 1/2 dia, 1/2 noite. Tese (Doutorado em Educação). 2007, 161p.Programa de Pós-Graduação em Educação, Faculdade de Educação, Universidade Federal do Rio Grande do Sul, Porto Alegre, 2007.

DELEUZE, Gilles. Diferença e repetição. Tradução Luiz Benedicto Lacerda Orlandi e Roberto Machado. Rio de Janeiro: Graal, 1988.

DELEUZE, Gilles. Foucault. Tradução Claudia Sant’Anna Martins. São Paulo: Brasilense, 2005.

DELEUZE, Gilles. A lógica do sentido. Tradução Luiz Roberto Salinas Fortes. São Paulo: Perspectiva, 2011.

DERRIDA, Jacques. Gramatologia. Tradução Miriam Schnaiderman e Renato Ribeiro Janine. São Paulo: Perspectiva, 1997.

DERRIDA, Jacques. Posições. Tradução Tomaz Tadeu da Silva. Belo Horizonte: Autêntica, 2001a.

DERRIDA, Jacques. Mal de arquivo: uma impressão freudiana. Tradução Claudia de Moraes Rego. Rio de Janeiro: Relume Dumará, 2001b.

DINARTE, Luiz Daniel Rodrigues. Congresso dos Signais. Didática filosófica do gesto. Proposta de Tese (Doutorado em Educação) 2016, 111p.. Programa de Pós-Graduação em Educação, Faculdade de Educação, Universidade Federal do Rio Grande do Sul, Porto Alegre, 2016. 
FARGE, Arlete. O sabor do arquivo. Tradução Fátima Murad. São Paulo: Editora da Universidade de São Paulo, 2009.

FONSECA, Tania Maria Galli. Vidas do Fora e a escrileitura de um mundo incontável. In: Vidas do fora: habitantes do silêncio; COSTA, Luciano Bedin da. Vidas do fora: habitantes do silêncio. Porto Alegre: Editora da UFRGS, 2010.

FOUCAULT, Michel. A arqueologia do saber. Tradução Luiz Felipe Baeta Neves. 7. ed. Rio de Janeiro: Forense Universitária, 2007.

FOUCAULT, Michel. Michel Foucault Explica Seu Último Livro. In:_ A arqueologia do saber _. Arqueologia das ciências e história dos sistemas de pensamento. Tradução Elisa Monteiro. 2 ed. Rio de Janeiro: Forense Universitária, 2008.

FOUCAULT, Michel. Microfisica do poder. Tradução Roberto Machado. 25. ed. São Paulo: Graal, 2012.

FOUCAULT, Michel. O nascimento de um mundo. In: Microfísica do poder. Filosofia, diagnóstico do presente e verdade. Rio de Janeiro: Forense Universitária, 2014.

HEUSER, Ester Maria Dreher. Construcionismo de uma crítica genealógica de escrileituras. In: Caderno de notas 8: ética e filosofia política em meio a diferença e ao Escrileituras. Cascavel: EDUNIOESTE, 2016.

NIETZSCHE, Friedrich Wilhelm. Genealogia da moral: uma polêmica. Tradução Paulo César de Souza. São Paulo: Companhia das Letras, 1998.

NIETZSCHE, Friedrich Wilhelm. O livro do filósofo. In:_Genealogia da moral. Introdução teorética sobre a verdade e a mentira no sentido extra-moral (verão de 1873). Tradução Rubens Eduardo Ferreira Frias. São Paulo: Centauro, 2001.

Informações sobre os Revisores:

\begin{tabular}{l||l} 
Língua & Nome: Lene Belon \\
Portuguesa & E-mail: lenebelon@hotmail.com
\end{tabular}

Língua Inglesa Nome: Lene Belon

E-mail: lenebelon@hotmail.com

Língua Espanhola Nome: Lene Belon

E-mail: lenebelon@hotmail.com 